\title{
WILDLIFE RESEARCH
}

\section{publish.csiro.au/wr}
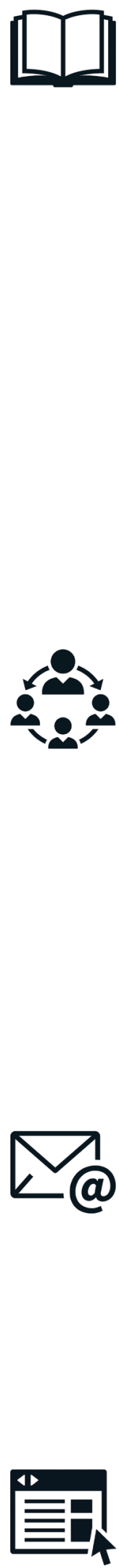

\section{SUBMIT YOUR ARTICLE ONLINE}

- Prepare: publish.csiro.au/wr/forauthors

- Submit: mc.manuscriptcentral.com/csiro-wr

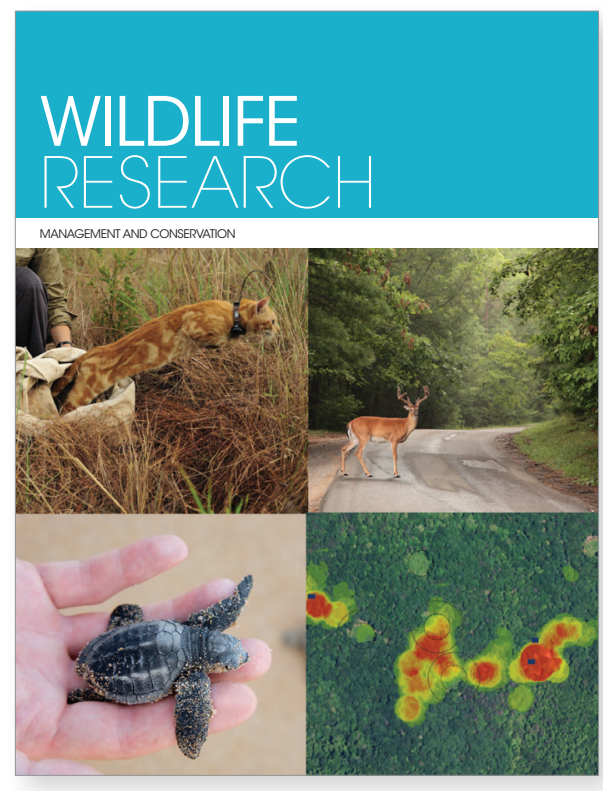

Editors-in-Chief:

Philip Stephens

Durham University

Andrea Taylor

Monash University

Aaron Wirsing

University of Washington

Publishing Model: Hybrid

Open Access options available

Frequency: 12 issues/year

Publishing since: 1974

eISSN: 1448-5494 (online)

C $O \mathbf{O}$ :

JM12809

As a member of the Committee on Publication Ethics (COPE), Wildlife

Research supports its core practices and is committed to transparency in scholarly publishing.

LEARN MORE ABOUT THE JOURNAL 


\section{JOURNAL METRICS}

\section{SPEED}

73 days from manuscript submission to first decision

71 days from manuscript acceptance to publication

\section{USAGE}

104,424 downloads in 2021

1142 Altmetrics mentions in 2021

\section{REJECTION RATE}

$\mathbf{5 4 \%}$ rejection rate in 2021

\section{IMPACT}

\# Ranking in area

52/176 in Zoology (Q2); 114/173 in Ecology (Q3)

2.2 Impact Factor

2.5 5-Year Impact Factor

TC $\mathbf{4 0 1 4}$ Total Citations in 2021

JcI 0.9 Journal Citation Indicator

\subsection{CiteScore}

CS Highest percentile 70\% (200/687 Ecology, Evolution, Behaviour and Systematics)

SNIP

\subsection{SNIP}

Source Normalised Impact per Paper

SJR

$0.7 \mathrm{SJR}$

SCImago Journal Rank

h5 23 h5-index

Google Scholar index for papers published 2017-21

\section{ABOUT CSIRO PUBLISHING}

CSIRO Publishing operates as an editorially independent science publisher within Australia's premier research group, Commonwealth Scientific and Industrial Research Organisation (CSIRO), and has been publishing journals since 1948. Our internationally recognised publishing program includes journals, books and magazines and covers a wide range of scientific disciplines.

\section{PARTNER ORGANISATIONS}

The Association of Society Publishers

Copyright Clearance Center

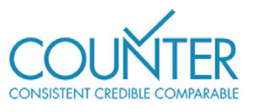

research4life
Crossref

Altmetric

$\$$ Dimensions

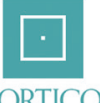

\section{publons}

